CLINICAL STUDY

\title{
Cytotoxic T lymphocyte antigen-4 Ala17 polymorphism is a genetic marker of autoimmune adrenal insufficiency: Italian association study and meta-analysis of European studies
}

\author{
Annalisa Brozzetti, Stefania Marzotti, Cristina Tortoioli, Vittorio Bini, Roberta Giordano ${ }^{1}$, Francesco Dotta ${ }^{2}$, \\ Corrado Betterle ${ }^{3}$, Annamaria De Bellis ${ }^{4}$, Giorgio Arnaldi ${ }^{5}$, Vincenzo Toscano ${ }^{6}$, Emanuela Arvat ${ }^{7}$, \\ Antonio Bellastella ${ }^{4}$, Franco Mantero ${ }^{3}$ and Alberto Falorni on behalf of the Italian Addison Network \\ Section of Internal Medicine and Endocrine and Metabolic Sciences, Department of Internal Medicine, University of Perugia, Via Enrico Dal Pozzo, O6126 \\ Perugia, Italy, ${ }^{1}$ Department of Clinical and Biological Sciences, University of Turin, ASO San Luigi Gonzaga, 10149 Orbassano, Italy, ${ }^{2}$ Department of \\ Internal Medicine and Endocrine and Metabolic Sciences, University of Siena, 53100 Siena, Italy, ${ }^{3}$ Department of Medical and Surgical Sciences, \\ University of Padova, 35122 Padova, Italy, ${ }^{4}$ Department of Clinical and Experimental Medicine and Surgery 'F. Magrassi, A. Lanzara', Second University \\ of Naples, 81100 Naples, Italy, ${ }^{5}$ Division of Endocrinology, Polytechnic University of Marche Region, 60126 Ancona, Italy, ${ }^{6}$ Department of Medical \\ Physiopathology, Second Faculty of Medicine, 'La Sapienza' University, 00189 Rome, Italy and ${ }^{7}$ Division of Endocrinology and Metabolism, Department of \\ Internal Medicine, University of Turin, 10126 Turin, Italy
}

(Correspondence should be addressed to A Falorni; Email: alberto.falorni@unipg.it)

\begin{abstract}
Objective: Cytotoxic T lymphocyte antigen-4 (CTLA4) gene polymorphism has been associated with human autoimmune diseases, but discordant data are available on its association with autoimmune Addison's disease (AAD). We tested the human leukocyte antigen (HLA)-independent association of CTLA4+49 (A/G) (Ala 17) and/or CTLA4 CT60 (A/G) polymorphism with AAD.

Design: DNA samples from 180 AAD patients and 394 healthy control subjects from continental Italy were analyzed, and association statistical analyses and meta-analysis of published studies were performed.

Methods: TaqMan minor groove binder chemistry assays and PCR fragment length polymorphism assays were used.

Results: Frequency of allele G of CTLA4 +49 was significantly increased among AAD patients $(40 \%$ alleles) than among healthy controls $(27 \%$ alleles; $P<0.0001)$. CTLA4 CT60 polymorphism was associated with AAD only in the heterozygous A/G individuals. The frequency of +49 AG + GG genotypes was significantly higher among $\mathrm{AAD}$ patients than among healthy control subjects, in both a co-dominant $(P<0.0001)$ and $G$ dominant model $(P<0.0001)$. CTLA4 +49 allele $G$ was significantly associated with disease risk in both patients with isolated AAD and in patients with autoimmune polyendocrine syndrome. Multivariate logistic regression analysis showed that CTLA4 +49 allele $\mathrm{G}$ was positively associated with $\mathrm{AAD}(P<0.0001$, odds ratio $(\mathrm{OR})=2.43,95 \%$ confidence interval $=1.54-3.86)$ also after correction for $D R B 1^{*} 03-D Q A 1^{*} 0501-D Q B 1^{*} 0201$, DRB $1^{*} 04$ $D Q A 1 * 0301-D Q B 1 * 0302$, and sex. Meta-analysis of five studies revealed a significant association of CTLA4 + 49 allele $\mathrm{G}$ with AAD $(P<0.0001)$ with an overall OR of $1.48(1.28-1.71)$.

Conclusions: The CTLA4+49 polymorphism is strongly associated with genetic risk for AAD, independently from the well-known association with HLA class II genes.
\end{abstract}

European Journal of Endocrinology 162 361-369

\section{Introduction}

Autoimmune Addison's disease (AAD) is the most frequent cause of primary adrenal insufficiency in western countries and Japan $(1,2)$, and is caused by an immunologically mediated destruction of the adrenocortical cells (3). Autoreactive T-cells are thought to play a critical role in the adrenal autoimmune process (3), and the disease is made evident by the appearance of circulating adrenal autoantibodies, mainly directed against the steroidogenic enzyme 21- $\beta$-hydroxylase autoantibodies (210HAb) (4-8). Human leukocyte antigen (HLA) class II genes $D R B 1, D Q A 1$, and $D Q B 1$ are the main genetic factors influencing the risk of disease (9). Similarly to other endocrine autoimmune diseases, HLA-DRB1*03-DQA1*0501-DQB1*0201 (DR3-DQ2) and DRB1*04-DQA1*0301-DQB1*0302 (DR4-DQ8) are positively and DRB1*0403 is negatively associated with risk for AAD (10-12). Other predisposing genetic factors include the CIITA gene, the PTPN22 gene, the vitamin D receptor gene, and the CYP27B1 gene (reviewed in (13)). However, the prevalence of 
AAD $(14,15)$ is much lower than that of other autoimmune diseases that share a similar genetic association with HLA haplotypes, and the precise mechanisms involved in the immune-mediated destruction of adrenocortical cells remain elusive.

T-cell activation requires both a signal provided by antigen-TCR engagement and co-stimulatory signal mainly provided by the interaction of CD28 with its ligand B7.1/B7.2 on antigen-presenting cells. The cytotoxic $\mathrm{T}$ lymphocyte antigen-4 (CTLA4) is a co-stimulatory molecule that binds to B7.1/B7.2, but provides negative signal to $\mathrm{T}$-cell activation via transduction of an intracellular signal and modulation of tryptophan catabolism in B7-expressing dendritic cells (16). Several investigations have been carried out to test the hypothesis that CTLA4 gene polymorphism contributes to genetic risk for autoimmune diseases. CTLA4 polymorphism has been found to be associated with Graves' disease, Hashimoto's thyroiditis, type 1 diabetes mellitus (T1DM), primary biliary cirrhosis, multiple sclerosis, celiac disease, and rheumatoid arthritis (17).

Discordant results have been generated for the genetic association of CTLA4 polymorphism with AAD. A first study of CTLA4 exon $1+49$ (A/G) (Ala17) polymorphism reported no statistically significant association with AAD in the German population (18), though AAD patients carrying the DQA $1^{*} 0501$ allele were significantly more CTLA4+49 G allelepositive than controls with the same DQA1 allele (18). Subsequent studies showed significant associations of CTLA4 microsatellite polymorphism (variant lengths of a dinucleotide (AT) $n$ repeat) within exon 3 (19) and of CTLA4+49 (Ala17) polymorphism (20) in English AAD patients. However, two more recent studies (21, 22 ) in two different European populations did not demonstrate a significant association between CTLA4 +49 polymorphism and AAD. An association with a series of polymorphisms different from Ala17 was observed in Norwegian and UK patients (22). The sequencing of the 300-kb region of chromosome 2 q33 enabled Ueda et al. (23) to demonstrate that the CT60 SNP was the most associated marker with some endocrine autoimmune diseases. Accordingly, the discordant results generated by the studies of CTLA4 polymorphism in AAD patients have not answered conclusively the question whether the CTLA4 gene contributes to the genetic risk for AAD or not.

A complicating factor is the frequent association of AAD with other autoimmune diseases - more often thyroid diseases, T1DM, or premature ovarian insufficiency - which configures the so-called autoimmune polyendocrine syndromes (APS) (3). Approximately two-thirds of AAD patients show clinical or subclinical manifestations of at least another autoimmune disease (3), thus making the identification of an AAD-specific genetic background somehow problematic. Furthermore, the frequency of at-risk HLA haplotypes in the general population varies greatly among countries (24), and the interplay between genetic and environmental factors may be profoundly different in different ethnic groups or geographic areas.

In our present study, we analyzed a large set of genomic DNA samples from AAD patients and healthy control subjects enrolled by the Italian Addison Network (IAN), to test the hypothesis that CTLA4+49 polymorphism is associated with the genetic risk for AAD in Italy. We also analyzed the CTLA4 CT60 polymorphism that was found to be positively associated with AAD in a previous study (22). The AAD patients were identified using a comprehensive flowchart that takes into consideration immunological, clinical, and biochemical data (25), so to minimize the possibility to include nonautoimmune cases in the studied population. The data were analyzed separately in APS patients and in patients with isolated $\mathrm{AAD}$, and the interaction between HLA class II polymorphism and CTLA4 gene polymorphism was tested by stratification analysis and multivariate logistic regression analysis. Finally, to better analyze the genetic contribution of CTLA4 polymorphism for AAD, we also performed metaanalysis of published results on CTLA4 exon $1+49$ (A/G) polymorphism.

\section{Materials and methods}

\section{Patients and control subjects}

Genomic DNA was available from 180 AAD patients and 394 healthy control subjects from continental Italy for the CTLA4 + $49(\mathrm{~A} / \mathrm{G})$, and from $153 \mathrm{AAD}$ patients and 242 healthy control subjects for the CTLA4 CT60 (A/G) genoptying.

IAN includes 14 endocrinological centers located in nine regions of continental Italy (24). Between January 1998 and April 2009, IAN has enrolled 372 patients with primary adrenal insufficiency. According to a recent update of diagnostic criteria for the etiological classification of primary adrenal insufficiency (25) and based on the combined use of immunological, biochemical, and clinical data, 260 cases (70\%) were reclassified as $\mathrm{AAD}$. Classification of $\mathrm{AAD}$ was based on the presence of $210 \mathrm{HAb}$ and/or adrenal cortex autoantibodies (ACA) in the absence of clinical, biochemical, or imaging signs of a nonautoimmune cause of adrenal insufficiency. Of the 260 AAD patients, genomic DNA was available for the present study from 180 AAD patients (median age at diagnosis: 36 years, range $8-73$ years; F/M ratio: 1.78). A total of 111 $(62 \%)$ cases had other clinical, subclinical, or latent autoimmune diseases and were classified as 'APS'. The remaining $69 \mathrm{AAD}$ patients were classified as 'isolated AAD'. APS I was excluded in all cases on the basis of clinical manifestations, and no APS I patient was included in our study. 
Blood samples collected during routine analyses, between March 1994 and December 2003, were available from 394 unrelated healthy control subjects (median age: 30 years, range $4-70$ years; F/M ratio:1.02) with no family history of endocrine autoimmune diseases. All patients and healthy individuals gave their informed consent for the study, and the study was approved by the local ethics committee.

\section{HLA-DR and -DQ genotyping}

HLA-DR and $-D Q$ genotyping was performed by SSO-dot blot analysis with modifications of a previously described method (26), and using sequence-specific oligonucleotides, $3^{\prime}$-end labeled with digoxigenin (Roche Diagnostics S.p.A). A chemiluminescent signal was generated by using alkaline phosphatase-labeled anti-digoxigenin (Roche) and CSPD (Roche). Chemiluminescence was measured in a microplate scintillation and luminescence counter (TopCount NXT, Packard Instrument Company, Meriden, CT, USA). Each membrane contained ten control samples with known HLA genotype.

HLA-DRB $1^{*} 04$ subtyping was performed by PCR-SSP with sequence-specific primers, according to the method described by Zetterquist \& Olerup (27).

\section{Genotyping of CTLA4}

The CTLA4 exon $1+49(\mathrm{~A} / \mathrm{G})$ and the CTLA4 CT60 (A/G) SNPs were analyzed with TaqMan SNP Genotyping Assays (Applied Biosystems, Foster City, CA, USA) using a Stratagene MX3000P QPCR System and MXPro QPCR Software. In addition, PCR restriction fragment length polymorphism assays (28) were also used for both SNPs to confirm genotyping results.

\section{Adrenal autoantibody assays}

$210 \mathrm{HAb}$ were tested using a previously published radiobinding assay with in vitro translated recombinant human ${ }^{35} \mathrm{~S}-210 \mathrm{H}$ (6). Antibody levels were expressed as a relative index (210HAb index), calculated as: (mean c.p.m. sample - mean c.p.m. of two negative standards)/(mean c.p.m. positive standard-mean c.p.m. of two negative standards), with the upper limit of normal values defined as the mean +3 S.D. of 200 healthy control subjects.

ACA were determined using indirect immunofluorescence on cryostatic sections of human adrenal glands (29). Levels of ACA were expressed as the reciprocal of the end point dilution titer.

\section{Statistical analysis of Italian data}

The odds ratio (OR) was calculated according to Woolf (30) and Miettinen (31). Differences in frequencies between patients and healthy control subjects were tested by the $\chi^{2}$ method with Yates' correction or the Fisher's exact test; the $P$ values were corrected for multiple testing. For the HLA haplotyping, the probability values were corrected for the number of comparisons, according to the number of HLA-DRB1, $-D Q A 1$, and $-D Q B 1$ alleles or haplotypes observed. For the CTLA4 polymorphism analysis, both a co-dominant model and G dominant model were applied. Differences in autoantibody levels (210HAb index) were tested by the nonparametric Mann-Whitney test.

The association of the dichotomous variables presence or absence of DQA1*0501-DQB1*0201, DQA $1^{*} 0301$ $D Q B 1 * 0302$, and CTLA4 $+49 \mathrm{G}$ allele with AAD, and its dependence on sex, was tested by multivariate logistic regression analysis. Results for logistic regression were expressed in terms of adjusted ORs and 95\% confidence interval (CI).

Absolute risk values for the development of AAD of combinations of HLA and CTLA4 +49 haplotypes/ alleles were estimated according to the available prevalence data of primary adrenal insufficiency in continental Italy (14) (117 cases per million, with 97\% ascertainment degree, making an estimated ratio of 120 cases per million) and the estimated frequency of AAD among Italian patients with primary adrenal insufficiency (minimum: $70 \%$, according to (32) and IAN data; maximum: $83 \%$, according to (3)). Accordingly, the estimated prevalence of AAD (non-APS I) in continental Italy is $84-100$ cases per million.

Linkage disequilibrium between the two CTLA4 SNPs studied was measured using the software MIDAS rel. 1.0(33).

Deviations from the Hardy-Weinberg equilibrium (HWE) were tested by comparison of observed and expected genotype frequencies. A $P$ value $<0.05$ was considered significant in all tests. All data analyses were performed using SPSS for Windows (release 13.0.; SPSS Inc., Chicago, IL, USA).

\section{Meta-analysis}

Identification and eligibility of studies We conducted MEDLINE, Current Contents, and Web of Science searches using 'adrenal insufficiency', 'Addison's disease', 'CTLA4', 'CTLA-4', and 'polymorphism' as keywords for papers published with no date restriction. No additional articles were identified through the references cited in the first series of articles selected. Articles included in meta-analysis were in any language, with human subjects, published in the primary literature and with no obvious overlap of subjects with other studies. Case-control studies were eligible if they had determined the distribution of genotypes in Addison's disease cases and in controls using a molecular method for genotyping. We identified four case-control studies $(18,20-22)$ that provided information on autoimmune Addison's disease occurrence associated with CTLA4 +49 A/G polymorphism. 
Data extraction and assessment of study quality For each study, we extracted the following characteristics: authors, year of publication, and characteristics of cases and controls (age at onset, sex ratio, ethnic group, and source of population), number of genotyped cases and controls, frequency of the genotypes, HWE, and ORs estimation. If ORs with $95 \% \mathrm{CI}$ or HWE assessment were not reported in the publication, we derived them from the raw data presented.

Meta-analysis We combined our data with that coming from literature revision using both fixed effects and random effect models. Heterogeneity among the studies was evaluated by the Cochrane's $Q$ test and was considered significant for $P<0.10$. To test for publication bias, both Begg's and Egger's tests $(34,35)$ were used. In a sensitivity analysis, we formally assessed the influence of individual studies on pooled estimates according to Tobias' method (36), in which if the point estimate of the pooled estimate with one study omitted lies outside the $\mathrm{CI}$ of the overall estimate with all available trials contributing, then the study in question has an excessive influence. Most calculations regarding meta-analysis were performed with computer program MIX Version 1.7 (37) (http://www.mix-for-metaanalysis.info).

\section{Results}

\section{CTLA4 exon $1+49$ (A/G) polymorphism is associated with genetic risk for $A A D$ in Italy}

None of the tested genetic variables showed significant deviations from HWE in the studied population.

Allele G of CTLA4+49 was significantly more frequent in the group of $\mathrm{AAD}$ patients than in the control group, with it being detected in 146/360 (40\%) AAD alleles and in 210/688 (27\%) healthy control alleles $(P<0.0001$; Table 1$)$. Thus, allele $\mathrm{G}$ was detected in $45 \%$ of healthy control subjects and in $69 \%$ of Addison patients (in either heterozygous or homozygous combination). The frequency of the AG+GG genotypes was significantly higher among AAD patients than among healthy control subjects, in both the co-dominant model $(P<0.0001)$ and $G$ dominant model $(P<0.0001$; $\mathrm{OR}=2.66$; 95\% CI: $1.83-3.86$ ). This association was not influenced by the presence/absence of other autoimmune diseases as allele $\mathrm{G}$ frequency was similar in isolated $\mathrm{AAD}$ and in $\mathrm{AAD}$ plus other autoimmune diseases (APS group; Table 1).

\section{CTLA4 CT60 (A/G) polymorphism in AAD}

Neither allele G nor allele A of CTLA4 CT60 polymorphism was significantly more frequent in AAD patients than in the control group, neither in the co-dominant model nor in the $\mathrm{G}$ dominant model (Table 2). A significant association with AAD was detected in A/G heterozygous individuals (91/153 (59\%) AAD patients compared with 116/242 (48\%) healthy control subjects; $P=0.033$ ), though this association was no longer significant after correction for a number of comparisons.

A significant linkage disequilibrium was detected between the CTLA4+49 SNP and the CTLA4 CT60 SNP $\left(D^{\prime}=0.762\right)$.

\section{CTLA4 exon $1+49$ (A/G) polymorphism is independently associated with AAD}

As expected, the HLA genotyping of the AAD patients revealed that $D R B 1^{*} 03-D Q A 1^{*} 0501-D Q B 1^{*} 0201$ (DR3-DQ2; $48 \%$ in AAD versus $14 \%$ in healthy control subjects, corrected $P=0.003$ ) and $D R B 1^{*} 04$ $D Q A 1 * 0301-D Q B 1 * 0302$ (DR4-DQ8; 23\% in AAD versus $6 \%$ in healthy control subjects, corrected $P=0.003)$ were positively and significantly associated with AAD.

Table 1 Genotype and allele frequencies for the cytotoxic T lymphocyte antigen-4 (CTLA4)+49 (A/G) polymorphism in Italian AAD patients.

\begin{tabular}{|c|c|c|c|c|c|c|c|c|c|c|c|c|}
\hline & & & & & \multicolumn{7}{|c|}{ Genotype frequencies } & \multirow[b]{3}{*}{$n$} \\
\hline & \multicolumn{4}{|c|}{ Allele frequencies } & \multicolumn{4}{|c|}{ Co-dominant model } & \multicolumn{3}{|c|}{ G dominant model } & \\
\hline & $A$ & $\mathrm{G}$ & MAF & $\begin{array}{l}\text { OR }(95 \% \mathrm{Cl}) \\
P \text { value }\end{array}$ & $\mathrm{AA}$ & $A G$ & GG & $P$ value & AA & $A G+G G$ & $\begin{array}{l}\text { OR }(95 \% \mathrm{Cl}) \\
P \text { value }\end{array}$ & \\
\hline $\begin{array}{l}\text { Total } \\
\text { AAD }\end{array}$ & 214 & 146 & 0.405 & $\begin{array}{c}1.88(1.44-2.44) \\
<0.0001\end{array}$ & 56 & 102 & 22 & $<0.0001$ & 56 & 124 & $\begin{array}{l}2.66(1.83-3.86) \\
<0.0001\end{array}$ & 180 \\
\hline $\begin{array}{l}\text { Isolated } \\
\text { AAD }\end{array}$ & 83 & 55 & 0.399 & $\begin{array}{l}1.82(1.25-2.66) \\
0.002\end{array}$ & 24 & 35 & 10 & 0.007 & 24 & 45 & $\begin{array}{l}2.25(1.32-3.84) \\
0.004\end{array}$ & 69 \\
\hline APS & 134 & 88 & 0.396 & $\begin{array}{l}1.81(1.32-2.47) \\
<0.0001\end{array}$ & 35 & 64 & 12 & $<0.0001$ & 35 & 76 & $\begin{array}{l}2.61(1.67-4.08) \\
<0.0001\end{array}$ & 111 \\
\hline $\begin{array}{l}\text { Healthy } \\
\text { controls }\end{array}$ & 578 & 210 & 0.266 & & 215 & 148 & 31 & & 215 & 179 & & 394 \\
\hline
\end{tabular}

MAF, minor allele frequency; OR (95\% Cl), odds ratio (95\% confidence interval); AAD, autoimmune Addison's disease; APS, autoimmune polyendocrine syndrome. 
Table 2 Genotype and allele frequencies for the cytotoxic T lymphocyte antigen-4 (CTLA4) CT60 (A/G) polymorphism in Italian AAD patients.

\begin{tabular}{|c|c|c|c|c|c|c|c|c|c|c|c|c|}
\hline & & & & & \multicolumn{7}{|c|}{ Genotype frequencies } & \multirow[b]{3}{*}{$n$} \\
\hline & \multicolumn{4}{|c|}{ Allele frequencies } & \multicolumn{4}{|c|}{ Co-dominant model } & \multicolumn{3}{|c|}{ G dominant model } & \\
\hline & $A$ & $G$ & MAF & $\begin{array}{l}\text { OR }(95 \% \mathrm{Cl}) \\
P \text { value }\end{array}$ & $A A$ & $A G$ & GG & $P$ value & $A A$ & $A G+G G$ & $\begin{array}{l}\text { OR }(95 \% \mathrm{Cl}) \\
P \text { value }\end{array}$ & \\
\hline $\begin{array}{l}\text { Total } \\
\text { AAD }\end{array}$ & 155 & 151 & 0.493 & $\begin{array}{l}1.11(0.84-1.48) \\
\text { NS }\end{array}$ & 32 & 91 & 30 & NS & 32 & 121 & $\begin{array}{l}1.57(0.97-2.53) \\
\text { NS }\end{array}$ & 153 \\
\hline $\begin{array}{l}\text { Isolated } \\
\text { AAD }\end{array}$ & 60 & 56 & 0.483 & $\begin{array}{l}1.07(0.71-1.6) \\
\text { NS }\end{array}$ & 12 & 36 & 10 & NS & 12 & 46 & $\begin{array}{l}1.59(0.8-3.18) \\
\text { NS }\end{array}$ & 58 \\
\hline APS & 98 & 92 & 0.484 & $\begin{array}{l}1.07(0.77-1.50) \\
\text { NS }\end{array}$ & 21 & 56 & 18 & NS & 21 & 74 & $\begin{array}{l}1.46(0.84-2.56) \\
\text { NS }\end{array}$ & 95 \\
\hline $\begin{array}{l}\text { Healthy } \\
\text { controls }\end{array}$ & 258 & 226 & 0.467 & & 71 & 116 & 55 & & 71 & 171 & & 242 \\
\hline
\end{tabular}

MAF, minor allele frequency; OR (95\% Cl), odds ratio (95\% confidence interval); AAD, autoimmune Addison's disease; APS, autoimmune polyendocrine syndrome; NS, not significant.

$D R B 1^{*} 0403$ was absent among the $D R B 1^{*} 04$ positive AAD patients, but was the most frequent DRB $1^{*} 04$ allele detected in healthy controls $(35 \%$ of $D R B 1^{*}$ 04-positive individuals; $\left.P<0.001\right)$.

Stratification of CTLA4 results according to HLA status is shown in Table 3. CTLA4 +49 allele $\mathrm{G}$ was detected in $68 \%$ of AAD patients negative for both HLADRB1*0301-DQA1*0501-DQB1*0201 (DR3-DQ2) and DRB1*04-DQA1*0301-DQB1*0302 (DR4-DQ8), in $67 \%$ of patients positive for HLA-DRB1*03DQA $1 * 0501-D Q B 1 * 0201$ (DR3-DQ2), and in 77\% of patients positive for HLA-DRB $1^{*} 04-D Q A 1 * 0301$ $D Q B 1^{*} 0302$ (DR4-DQ8) ( $P=$ not significant). The highest OR $(>20)$ was observed for the heterozygous DRB1*03-DQA1*0501-DQB1*0201 (DR3-DQ2)/DRB1 *04-DQA1*0301-DQB1*0302 (DR4-DQ8) individuals who were also positive for the CTLA4 +49 allele G, this combination being present in $9.4 \%$ of AAD patients and in only $0.5 \%$ of healthy control subjects (Table 3 ). On the other hand, the absence of all the three major genetic markers was significantly and negatively associated with disease risk, with an overall OR lower than 0.2 (Table 3). The presence of the CTLA4+49 allele $\mathrm{G}$ increased 3.2- to 3.7-fold the OR associated with the combination of at-risk HLA class II haplotypes (Table 3). Based on a prevalence ratio of 84-100 cases per million in continental Italy, estimated absolute risk values for $\mathrm{AAD}$ ranged from 1/532-1/633 in Italian subjects positive for all the three major genetic markers to $1 / 34,531-1 / 41,109$ in subjects negative for all of them (Table 3).

The circulating levels of $210 \mathrm{HAb}$ were not significantly associated with CTLA4+49 (A/G) polymorphism, as $210 \mathrm{HAb}$ index was 0.713 (range 0.005-2.244) in allele G-negative AAD patients and 0.648 (range 0-5.332) in allele G-positive AAD patients $(P=\mathrm{NS})$.

To better define the independent contribution of CTLA4 +49 polymorphism to genetic susceptibility for
AAD, we then performed multivariate logistic regression analysis. DRB 1*0403 could not be included in this model because of co-linearity problems (with $B=-20.8 \pm 9655)$, and the frequency of the CTLA $4+49$ allele $\mathrm{G}$ was tested in DRB1*04-positive healthy individuals who were positive or negative for the DRB ${ }^{*} 0403$ subtype. The CTLA4 +49 allele $\mathrm{G}$ was equally frequent in $D R B 1^{*} 0403$-positive and $D R B 1^{*} 0403-$ negative healthy control subjects carrying the $D R B 1 * 04-D Q B 1 * 0301-D Q B 1 * 0302$ (DR4-DQ8) haplotype $(27 \%$ in both groups), which shows that the association of CTLA4 gene polymorphism with AAD did not depend on $D R B 1^{*} 0403$. In the multivariate logistic regression model, DRB $1^{*} 03-D Q A 1^{*} 0201$ DQB1*0501 (DR3-DQ2), DRB1*04-DQA 1*0301DQB1*0302 (DR4-DQ8), CTLA4 +49 allele G, and sex were included as independent variables. All the variables found to be associated at the univariate analysis were also found to be independently associated with AAD, after correction for sex (Table 4). Thus, frequency of CTLA4 allele G continued to be positively associated with genetic risk for the disease $(P<0.0001$, $\mathrm{OR}=2.43,95 \% \mathrm{CI}=1.54-3.86$ ), also after correction for DRB1*03-DQA1*0501-DQB1*0201 (DR3-DQ2) and DRB 1*04-DQA 1*0301-DQB1*0302 (DR4-DQ8). In addition, the correction for sex in the multivariate analysis also excludes the possibility that the association of CTLA4 with AAD was influenced by a different sex distribution among patients and healthy control subjects. When the multivariate logistic regression analysis was repeated for isolated AAD patients and for APS patients, similar results were obtained (Table 4). CTLA4 allele $\mathrm{G}$ continued to be independently associated with disease risk even when the number of $\mathrm{G}$ alleles was included in the analysis, instead of presence or absence of $\mathrm{G}(P=0.002 ; \mathrm{OR}=1.75,95 \% \mathrm{CI}=1.23-2.47$ in total AAD patients; $P=0.037$; $O R=1.70$, 95\% $\mathrm{CI}=1.03-$ 2.79 in isolated AAD patients; and $P=0.014 ; \mathrm{OR}=$ $1.70,95 \% \mathrm{CI}=1.11-2.58$ in APS patients). 


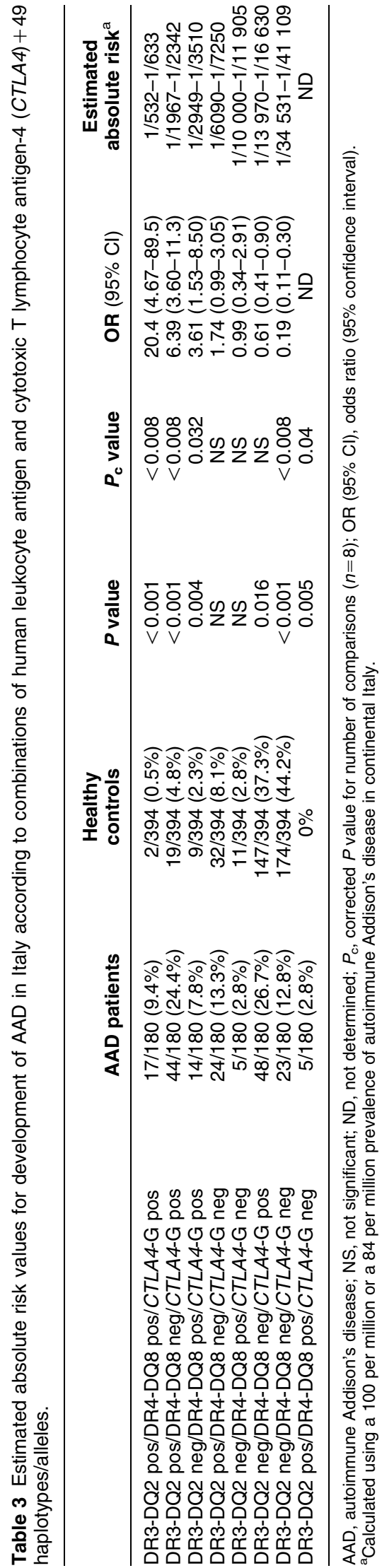

\section{Meta-analysis of association studies of CTLA4 + 49 (A/G) polymorphism in AAD}

We identified four case-control studies that provided information on $\mathrm{AAD}$ occurrence associated with the CTLA4+49 (A/G) polymorphism $(18,20-22)$. Thus, five studies were included in the meta-analysis (including our present Italian study; Fig. 1). CTLA4 +49 (A/G) data showed no significant deviations from HWE in any of the five studies.

The meta-analysis showed a positive and significant association between the CTLA4+49 (A/G) polymorphism and AAD in the five studies $(P<0.0001)$ with a global OR of $1.48(1.28-1.71$; Fig. 1). The Cochrane's $Q$ test did not detect any significant heterogeneity of OR $(P=0.3)$ among the studied populations. The sensitivity analysis did not result in loss of statistical significance by excluding one study at a time. The random and fixed effects models provided similar results.

\section{Discussion}

The cytotoxic T lymphocyte antigen-4 (CTLA4) gene has emerged as an important susceptibility locus for autoimmune endocrinopathies (17). However, controversial data have been published for the association of CTLA4 polymorphism with AAD (18-22). In our present study, we demonstrate that CTLA4 exon $1+49$ (A/G) (Ala17) polymorphism is significantly associated with disease risk in AAD patients from continental Italy. In spite of a strong linkage disequilibrium with CTLA4+49 (A/G), the CTLA4 CT60 (A/G) polymorphism was not found to be significantly associated with $\mathrm{AAD}$ in our study, contrarily to what was observed in other populations (22). We also show that isolated AAD is associated with CTLA4+49 polymorphism, thus excluding the possibility that the genetic association might be due to the high frequency of other autoimmune diseases in patients with AAD. We performed both stratification analysis and logistic regression analysis to demonstrate that CTLA4 +49 $(\mathrm{A} / \mathrm{G})$ polymorphism is independently associated with genetic risk for $\mathrm{AAD}$, and that allele $\mathrm{G}$ is increasing the risk to develop clinical AAD. Finally, to resolve the controversy generated by previous association studies in AAD (18-22), we performed meta-analysis that included all studies currently available on CTLA $4+49$ allele $\mathrm{G}$ frequency in Addisonian patients. The results of this meta-analysis clearly provide further indication that CTLA4+49 allele $\mathrm{G}$ contributes to the genetic background predisposing for AAD.

Several hypotheses can be formulated to explain the discrepancies among different studies of CTLA4+49 $(\mathrm{A} / \mathrm{G})$ polymorphism in AAD. First, the number of AAD patients studied in the reference populations ranged from 57 to $134(18,20-22)$, and the low number of 
Table 4 Results of multivariate logistic regression analysis for association with autoimmune Addison's disease in Italy.

\begin{tabular}{|c|c|c|c|c|c|}
\hline Factors & Estimate & S.E.M. & Wald $\chi^{2}$ & $P$ & OR (95\% Cl) \\
\hline \multicolumn{6}{|l|}{ Total AAD patients } \\
\hline$D R B 1^{*} 03-D Q A 1^{\star} 0501-D Q B 1^{\star} 0201$ & 1.686 & 0.243 & 48.231 & $<0.0001$ & $5.40(3.35-8.68)$ \\
\hline$D R B 1^{\star} 04-D Q A 1^{\star} 0301-D Q B 1^{*} 0302$ & 1.238 & 0.335 & 13.634 & $<0.0001$ & $3.45(1.79-6.65)$ \\
\hline CTLA4+ 49 allele $\mathrm{G}$ & 0.890 & 0.235 & 14.377 & $<0.0001$ & $2.43(1.54-3.86)$ \\
\hline \multicolumn{6}{|l|}{ Isolated AAD patients } \\
\hline$D R B 1^{\star} 03-D Q A 1^{\star} 0501-D Q B 1^{\star} 0201$ & 1.933 & 0.340 & 32.361 & $<0.0001$ & $6.91(3.55-13.45)$ \\
\hline$D R B 1^{*} 04-D Q A 1^{\star} 0301-D Q B 1^{*} 0302$ & 0.980 & 0.510 & 3.696 & 0.048 & $2.67(1.02-7.24)$ \\
\hline CTLA4+ 49 allele $\mathrm{G}$ & 0.687 & 0.351 & 3.826 & 0.049 & $1.99(1.01-3.95)$ \\
\hline \multicolumn{6}{|l|}{ APS patients } \\
\hline$D R B 1^{\star} 03-D Q A 1^{\star} 0501-D Q B 1^{\star} 0201$ & 1.583 & 0.303 & 27.257 & $<0.0001$ & $4.871(2.67-8.83)$ \\
\hline$D R B 1^{\star} 04-D Q A 1^{*} 0301-D Q B 1^{*} 0302$ & 1.514 & 0.394 & 14.795 & $<0.0001$ & $4.543(2.10-9.82)$ \\
\hline CTLA4+ 49 allele $\mathrm{G}$ & 0.876 & 0.299 & 8.584 & 0.003 & $2.402(1.34-4.32)$ \\
\hline
\end{tabular}

OR $(95 \% \mathrm{Cl})$, odds ratio (95\% confidence interval).

cases may explain the lack of statistical significance in some studies. Secondly, primary adrenal insufficiency may be caused by a nonautoimmune process (posttuberculosis, post-paracoccidioidomycosis, adrenoleukodystrophy, adrenal hemorrhage, sepsis, genetic disorders, or others), and only an accurate etiological classification of each patient can ensure that only autoimmune cases are included in the studied population. Given the low number of cases enrolled in some studies, the inclusion of nonautoimmune patients may critically reduce the power of the statistical analysis. For this reason, the IAN has developed a comprehensive flowchart for the accurate classification of primary adrenal insufficiency and the identification of patients with AAD (25), which has enabled us to include in our study only patients with a demonstrated adrenal autoimmune process. Thirdly, the high frequency of the low penetrance disease CTLA4 alleles in the normal general population (23) could also explain the difficulties in confirming the association in different populations. Finally, the risk of developing primary adrenal insufficiency is not dramatically different among European countries - ranging from 120 cases per million in Italy (14) to 140 cases per million in Norway (15) - but the frequency of at-risk HLA haplotypes is two- to three-fold higher in Scandinavia than in Southern Europe. Accordingly, non-HLA genes, as well as environmental factors, must play a critical role in modulating the risk for $\mathrm{AAD}$. In addition, one cannot exclude the possibility that the weight of each specific gene might differ in different geographic areas, under the pressure of a specific environment, thus making possible that a gene marker is strongly associated with disease risk in one country, but not in another.

The CTLA4 +49 allele $\mathrm{G}$ is significantly increased in patients with T1DM or thyroid autoimmune diseases, and in some studies, it has been postulated that AAD would be associated with CTLA4 polymorphism when in the context of APS $(18,20)$. Our study shows that $\mathrm{AAD}$ is associated with this gene marker also in patients with no other manifestation of autoimmunity, thus supporting the hypothesis that CTLA4 polymorphism contributes to the genetic background for adrenal autoimmunity. Nevertheless, AAD shares the major genetic predisposing markers with other endocrine autoimmune diseases, and at present it is not yet possible to resolve the specific genetic background of each disease component of APS. It had been proposed that the $D R B 1{ }^{*} 0404$ subtype might discriminate AAD patients from T1DM patients $(12,38)$, but the frequency of *0404 in the general population cannot provide an explanation for the high difference in prevalence between T1DM and AAD. In addition, no selective association with ${ }^{*} 0404$ was found in our previous study in Italian AAD patients, in which only the ${ }^{*} 0403$ subtype was found to be strongly and negatively associated with both T1DM and AAD (11).

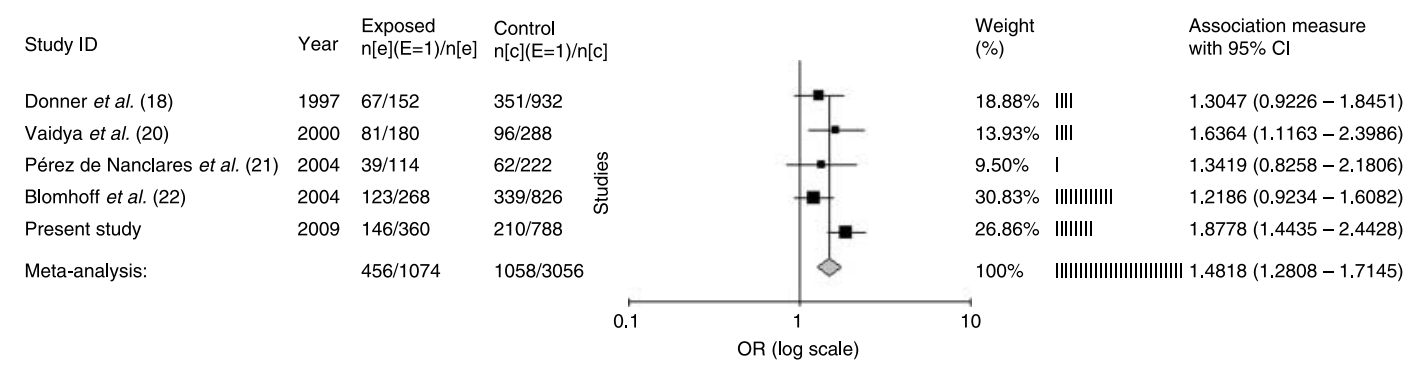

Figure 1 Odds ratio meta-analysis plot of the association of CTLA4+49 (A/G) polymorphism with AAD. 
It is unclear why we could not reproduce the results of other studies (23) regarding association of the CTLA4 CT60 polymorphism with AAD. One possibility is that the number of subjects studied did not ensure sufficient power to the statistical analysis. So we cannot rule out the possibility that this polymorphism might be associated with adrenal insufficiency also in the Italian population. However, based on our data, we can exclude an OR higher than 1.4, much lower than the one observed with the CTLA4+49 polymorphism. The observed CTLA4 CT60 allele frequency in our Italian control population is similar to that reported in a previous study from a different country (22). On the other hand, the frequency of allele $\mathrm{G}$ of CTLA4+49 was much lower in our Italian controls than in controls from other European countries in previous studies $(18,22)$, which may explain why a strong association to AAD for the $G$ allele of CTLA $4+49$ was found in Italy, but not in the other two above-mentioned cohorts.

At present, it is still unclear how gene polymorphism might influence CTLA 4 function. It has been proposed that the predisposing alleles might influence the levels of circulating soluble CTLA-4 (sCTLA-4) (23). A reduction in sCTLA-4 level could determine the blocking of CD80/CD86 molecules, with subsequent T-cell activation through $\mathrm{CD} 28$ (23). Alternatively, higher levels of sCTLA-4 could compete with membrane-bound CTLA-4 for CD80/CD86-binding sites, thus causing a reduction of inhibitory signaling.

In conclusion, our study provides data indicating that CTLA4 polymorphism modulates the genetic risk for AAD. Further studies are needed to unravel the molecular mechanisms of genetic predisposition to $\mathrm{AAD}$ and to expand our knowledge of the effects of the predisposing alleles/haplotypes on the development of the adrenal autoimmune process.

\section{Declaration of interest}

The authors declare that there is no conflict of interest that could be perceived as prejudicing the impartiality of the research reported.

\section{Funding}

This research was funded by EU FP7, Grant number 201167, Euradrenal to A Falorni and C Betterle.

\section{Author contribution statement}

In addition to the authors, the following members of the Italian Addison Network contributed to the collection of data and blood samples from patients with primary adrenal insufficiency: B Ambrosi (Milan), A Angeli (Orbassano), A Baccarelli (Milan), L Barbetta (Milan), G Basta (Perugia), P Beck-Peccoz (Milan), A Bizzarro (Naples), M Boscaro (Ancona), F Calcinaro (Perugia), F Cavagnini (Milan), R Celleno (Perugia), C Dal Prà (Padova), E Ghigo (Turin), S Laureti (Perugia), R Libè (Milano), F Loré (Siena), M Mannelli (Florence), G Mantovani (Milan), P Paccotti (Orbassano), F Pecori Giraldi (Milan), R Perniola (Lecce), F Santeusanio (Perugia), M Terzolo (Turin), C Tiberti (Rome), P Toja (Milan), M Torlontano (S Giovanni Rotondo), $\mathrm{V}$ Trischitta (S Giovanni Rotondo), R Zanchetta (Padova).

\section{References}

1 Oelkers W. Adrenal insufficiency. New England Journal of Medicine $19963351206-1212$.

2 Nomura K, Depura H \& Saruta T. Addison's disease in Japan: characteristics and changes revealed in a nationwide survey. Internal Medicine 199433 602-606.

3 Betterle C, Dal Pra C, Mantero F \& Zanchetta R. Autoimmune adrenal insufficiency and autoimmune polyendocrine syndromes: autoantibodies, autoantigens, and their applicability in diagnosis and disease prediction. Endocrine Reviews 200223 327-364.

4 Winqvist O, Karlsson FA \& Kämpe O. 21-Hydroxylase, a major autoantigen in idiopathic Addison's disease. Lancet 1992339 1559-1562.

5 Bednarek J, Furmaniak J, Wedlock N, Kiso Y, Baumann-Antczak A, Fowler S, Krishnan H, Craft JA \& Rees Smith B. Steroid 21-hydroxylase is a major autoantigen involved in adult onset autoimmune Addison's disease. FEBS Letters 1992309 51-55.

6 Falorni A, Nikoshkov A, Laureti S, Grenbäck E, Hulting AL, Casacci G, Santeusanio F, Brunetti P, Luthman H \& Lernmark A. High diagnostic accuracy for idiopathic Addison's disease with a sensitive radiobinding assay for autoantibodies against recombinant human 21-hydroxylase. Journal of Clinical Endocrinology and Metabolism $1995 \mathbf{8 0} 2752-2755$.

7 Tanaka H, Perez MS, Powell M, Sanders JF, Sawicka J, Chen S, Prentice L, Asawa T, Betterle C, Volpato M, Rees Smith B \& Furmaniak J. Steroid 21-hydroxylase autoantibodies: measurements with a new immunoprecipitation assay. Journal of Clinical Endocrinology and Metabolism 199782 1440-1446.

8 Falorni A, Laureti S, Nikoshkov A, Picchio ML, Hallengren B, Vandewalle CL, Gorus FK, Belgian Diabetes Registry, Tortoioli C, Luthman H, Brunetti P \& Santeusanio F. 21-Hydroxylase autoantibodies in adult patients with endocrine autoimmune diseases are highly specific for Addison's disease. Clinical and Experimental Immunology $1997 \mathbf{1 0 7} 341-345$.

9 Robles DT, Fain PR \& Eisenbarth GS. The genetics of autoimmune polyendocrine syndrome type II. Endocrinology and Metabolism Clinics of North America 200231 353-368.

10 Maclaren NK \& Riley WJ. Inherited susceptibility to autoimmune Addison's disease is linked to human leukocyte antigens-DR3 and/or DR4, except when associated with type I autoimmune polyglandular syndrome. Journal of Clinical Endocrinology and Metabolism $1986 \mathbf{6 2} 455-459$.

11 Gambelunghe G, Kockum I, Bini V, De Giorgi G, Celi F, Betterle C, Giordano R, Libè R \& Falorni A. Retrovirus-like long-terminal repeat DQ-LTR 13 and genetic susceptibility to type 1 diabetes and autoimmune Addison's disease. Diabetes $2005 \mathbf{5 4} 900-905$.

12 Myhre AG, Undlien DE, Løvås K, Uhlving S, Nedrebø BG, Fougner KJ, Trovik T, Sørheim JI \& Husebye ES. Autoimmune adrenocortical failure in Norway autoantibodies and human leukocyte antigen class II associations related to clinical features. Journal of Clinical Endocrinology and Metabolism $2002 \mathbf{8 7}$ 618-623.

13 Falorni A, Brozzetti A, La Torre D, Tortoioli C \& Gambelunghe G. The association of genetic polymorphisms and autoimmune Addison's disease. Expert Review of Clinical Immunology 20084 441-456.

14 Laureti S, Vecchi L, Santeusanio F \& Falorni A. Is the prevalence of Addison's disease underestimated? Journal of Clinical Endocrinology and Metabolism $1999 \mathbf{8 4} 1762$.

15 Løvås K \& Husebye ES. High prevalence and increasing incidence of Addison's disease in western Norway. Clinical Endocrinology 200256 787-791.

16 Grohmann U, Orabona C, Fallarino F, Vacca C, Calcinaro F, Falorni A, Candeloro P, Belladonna ML, Bianchi R, Fioretti MC \& Puccetti P. CTLA-4-Ig regulates tryptophan catabolism in vivo. Nature Immunology 20023 1097-1101.

17 Vaidya B \& Pearce S. The emerging role of the CTLA-4 gene in autoimmune endocrinopathies. European Journal of Endocrinology $2004150619-626$. 
18 Donner H, Braun J, Seidl C, Rau H, Finke R, Ventz M, Walfish PG, Usadel KH \& Badenhoop K. Codon 17 polymorphism of the cytotoxic T lymphocyte antigen 4 gene in Hashimoto's thyroiditis and Addison's disease. Journal of Clinical Endocrinology and Metabolism 199782 4130-4132.

19 Kemp EH, Ajjan RA, Husebye ES, Peterson P, Uibo R, Imrie H, Pearce SH, Watson PF \& Weetman AP. A cytotoxic T lymphocyte antigen-4 (CTLA-4) gene polymorphism is associated with autoimmune Addison's disease in English patients. Clinica Endocrinology 199849 609-613.

20 Vaidya B, Imrie H, Geatch DR, Perros P, Ball SG, Baylis PH, Carr D, Hurel SJ, James RA, Kelly WF, Kemp EH, Young ET, Weetman AP, Kendall-Taylor P \& Pearce SH. Association analysis of the cytotoxic T lymphocyte antigen-4 (CTLA-4) and autoimmune regulator-1 (AIRE-1) genes in sporadic autoimmune Addison's disease. Journal of Clinical Endocrinology and Metabolism $2000 \mathbf{8 5}$ 688-691.

21 Pérez de Nanclares G, Martín-Pagola A, Ramón Bilbao J, Vázquez F \& Castaño L. No evidence of association of CTLA-4 polymorphisms with Addison's disease. Autoimmunity 200437 453-456.

22 Blomhoff A, Lie BA, Myhre AG, Kemp EH, Weetman AP, Akselsen HE, Huseby ES \& Undlien DE. Polymorphisms in the cytotoxic T lymphocyte antigen-4 gene region confer susceptibility to Addison's disease. Journal of Clinical Endocrinology and Metabolism 200489 3474-3476.

23 Ueda H, Howson JM, Esposito L, Heward J, Snook H, Chamberlain G, Rainbow DB, Hunter KM, Smith AN, Di Genova G, Herr MH, Dahlman I, Payne F, Smyth D, Lowe C, Twells RC, Howlett S, Healy B, Nutland S, Rance HE, Everett V, Smink LJ, Lam AC, Cordell HJ, Walker NM, Bordin C, Hulme J, Motzo C, Cucca F, Hess JF, Metzker ML, Rogers J, Gregory S, Allahabadia A, Nithiyananthan R, Tuomilehto-Wolf E, Tuomilehto J, Bingley P, Gillespie KM, Undlien DE, Rønningen KS, Guja C, Ionescu-Tîrgovişte C, Savage DA, Maxwell AP, Carson DJ, Patterson CC, Franklyn JA, Clayton DG, Peterson LB, Wicker LS, Todd JA \& Gough SC. Association of the T-cell regulatory gene CTLA-4 with susceptibility to autoimmune disease. Nature $2003 \mathbf{4 2 3} 506-511$.

24 Ronningen KS, Keiding N, Green A \& EURODIAB ACE Study Group. Correlations between the incidence of childhood-onset type I diabetes in Europe and HLA genotypes. Diabetologia 2001 44 B 51-B59.

25 Falorni A, Laureti S, De Bellis A, Zanchetta R, Tiberti C, Arnaldi G, Bini V, Beck-Peccoz P, Bizzarro A, Dotta F, Mantero F, Bellastella A, Betterle C \& Santeusanio F. Italian Addison Network study: update of diagnostic criteria for the etiological classification of primary adrenal insufficiency. Journal of Clinical Endocrinology and Metabolism 200489 1598-1604.
26 Gambelunghe G, Ghaderi M, Tortoioli C, Falorni A, Santeusanio F, Brunetti P, Sanjeevi CB \& Falorni A. Two distinct MICA gene markers discriminate major autoimmune diabetes types. Journal of Clinical Endocrinology and Metabolism 200186 3754-3760.

27 Zetterquist $\mathrm{H}$ \& Olerup O. Identification of the HLA-DRB1*04, -DRB $1 * 07$, and -DRB $1 * 09$ alleles by PCR amplification with sequence-specific primers (PCR-SSP) in 2 hours. Human Immunology 199234 64-74.

28 Marron MP, Raffel LJ, Garchon HJ, Jacob CO, Serrano-Rios M, Martinez Larrad MT, Teng WP, Park Y, Zhang ZX, Goldstein DR, Tao YW, Beaurain G, Bach JF, Huang HS, Luo DF, Zeidler A, Rotter JI, Yang MC, Modilevsky T, Maclaren NK \& She JX. Insulindependent diabetes mellitus (IDDM) is associated with CTLA4 polymorphism in multiple ethnic groups. Human Molecular Genetics 19976 1275-1282.

29 Betterle C, Scalici C, Presotto F, Pedini B, Moro L, Rigon F \& Mantero F. The natural history of adrenal function in autoimmune patients with adrenal autoantibodies. Journal of Endocrinology $1988117467-475$.

30 Woolf $\mathrm{B}$. On estimating the relation between blood group and disease. Annals of Human Genetics 199519 251-253.

31 Miettinen OS. The estimability and estimation in case-referent studies. American Journal of Epidemiology 1976103 226-235.

32 Betterle C, Scalici C, Pedini B \& Mantero F. Morbo di Addison: principali associazioni cliniche e descrizione della storia naturale della malattia. Annali Italiani di Medicina Interna 19894 195-206.

33 Gaunt TR, Rodriguez S, Zapata C \& Day IN. MIDAS: software for analysis and visualisation of interallelic disequilibrium between multiallelic markers. BMC Bioinformatics 200627227.

34 Begg CB \& Mazumdar M. Operating characteristics of a rank correlation test for publication bias. Biometrics $1994 \mathbf{5 0}$ 1088-1101.

35 Egger M, Smith GD, Schneider M \& Minder C. Bias in meta-analysis detected by a simple, graphical test. BMJ $1997315629-634$.

36 Tobias A. Assessing the influences of a single study in metaanalysis. Stata Technical Bulletin 199947 15-17.

37 Bax L, Yu LM, Ikeda N, Tsuruta H \& Moons KGM. Development and validation of MIX: comprehensive free software for meta-analysis of causal research data. BMC Medical Research Methodology 2006650.

38 Yu L, Brewer KW, Gates S, Wu A, Wang T, Babu SR, Gottlieb PA, Freed BM, Noble J, Erlich HA, Rewers MJ \& Eisenbarth GS. DRB $1 * 04$ and DQ alleles: expression of 21-hydroxylase autoantibodies and risk of progression to Addison's disease. Journal of Clinical Endocrinology and Metabolism 199984 328-335.

Received 28 October 2009

Accepted 1 November 2009 